\title{
Flutuação do desempenho acadêmico de alunos de medicina selecionados por políticas afirmativas (PIMESP)
}

\section{Fluctuation of academic performance of medical students selected by affirmative action policies (PIMESP)}

\author{
Atílio Marcomini Neto' (D) $\mid$ atiliocsp@gmail.com \\ Patrícia da Silva Fucuta' (1D) patriciafucuta@gmail.com \\ Vânia Maria Sabadotto Brienze' (D) vania.brienze@hospitaldebase.com.br \\ Alba Regina de Abreu Lima' (D) alba.lima09@gmail.com \\ Sérgio Luís Aparecido Brienze' (D) sergio.brienze@famerp.br \\ Júlio César André1 (1) julio.andre@famerp.br
}

\section{RESUMO}

Introdução: Depois de quase 20 anos desde o início da materialização das ações afirmativas, ainda há muita discussão sobre a real efetividade dessas medidas, principalmente, no que tange ao desempenho acadêmico, quando se comparam "cotistas" e "não cotistas", surgindo dúvidas se aqueles conseguem acompanhar estes.

Objetivo: Este estudo teve como objetivos traçar um perfil do desempenho acadêmico e compará-lo e os demais aspectos relacionados à vida acadêmica dos alunos "cotistas" (Programa de Inclusão com Mérito no Ensino Superior Público Paulista - Pimesp) com os demais alunos de suas respectivas turmas selecionados via ampla concorrência (AC).

Método: Trata-se de coorte retrospectiva de alunos da primeira à terceira série de Medicina, divididos em AC ou Pimesp. Avaliaram-se os seguintes aspectos: média aritmética das notas finais das disciplinas curriculares, situação final de aprovação nas disciplinas (SFA), frequência, títulos emprestados na biblioteca (TEB) e participação em monitorias/centro acadêmico. As variáveis contínuas foram comparadas pelo teste $t$ de Student ou Mann-Whitney, e as categóricas, por qui-quadrado ou exato de Fisher. Valores $p<0,05$ foram considerados significantes.

Resultado: Participaram do estudo 237 alunos. Todos haviam concluído a primeira série (ingressantes de 2015, 2016 e 2017); 158 alunos (ingressantes de 2015 e 2016), a primeira e segunda séries; e 78 (32,9\%) haviam concluído a terceira série (ingressantes de 2015) no momento da pesquisa. Na análise de todos os que haviam concluído a primeira série, dos quais $16 \%$ faziam parte do Pimesp, houve diferença nas médias das notas finais e da SFA, maior para alunos AC, e não houve diferença para frequência, TEB, participação em monitorias e centro acadêmico. Na análise dos que haviam concluído a segunda série, dos quais 15,8\% faziam parte do Pimesp, não houve diferença entre nenhuma das variáveis estudadas. A análise dos que haviam concluído a terceira série, dos quais 15,4\% faziam parte do Pimesp, mostrou novamente diferença entre as médias das notas finais e da SFA maior para alunos $\mathrm{AC}$, porém com uma diferença menos acentuada, e não houve diferenças significativas para as demais variáveis.

Conclusão: Observou-se flutuação do desempenho acadêmico dos estudantes Pimesp, para menor, em relação aos estudantes AC, ao longo dos três primeiros anos do curso de Medicina, mas não para outras variáveis. Não foi observado aumento do índice de evasão, contrariando a literatura. Palavras-chave: Educação Médica; Ações Afirmativas; Estudantes de Medicina; Desempenho Acadêmico.

\section{ABSTRACT}

Introduction: Almost 20 years since the beginning of affirmative action implementation, there is still much discussion about the real effectiveness of these measures, especially regarding academic performance, comparing "quota holders" to "non-quota holders", with doubts arising about whether the former can keep up with the latter.

Objective: To establish a profile and compare the academic performance and other aspects related to the academic life of "quota holder" students (Inclusion Program with Merit in Public Higher Education in São Paulo - PIMESP) with the other students in their respective classes selected via broad competition (BC).

Method: Retrospective cohort of $1^{\text {st }}$ to $3^{\text {rd }}$-year medical students, divided in BC or PIMESP. The following were assessed: arithmetic mean of the final grades of the curricular subjects; final approval status (FAS) in the subjects; frequency; books borrowed from the library (BBLi) and participation in monitoring/ academic center. Continuous variables were compared by Student's t-test or Mann-Whitney test and categorical by chi-square or Fisher's exact test. Values $p<0.05$ were considered significant.

Results: Of the 237 students included in the sample, all had completed the $1^{\text {st }}$ year (2015, 2016 and 2017 entrants), 158 students (2015 and 2016 entrants) the $1^{\text {st }}$ and $2^{\text {nd }}$ years, and 78 (32.9\%) had completed the $3^{\text {rd }}$ year (2015 entrants) at the time of the survey. In the analysis of all those who had completed the $1^{\text {st }}$ year, where $16 \%$ were PIMESP, there was a difference in mean final grades and FAS, higher for BC students and no difference for attendance, BBLi, participation in monitoring and academic center. In the analysis of those who had completed the $2^{\text {nd }}$ year, where $15.8 \%$ were PIMESP, there was no difference between any of the studied variables. The analysis of those who had completed the $3^{\text {rd }}$ year, where 15.4\% were PIMESP, once again showed difference between the averages of final grades and FAS, higher for BC students, but with a less marked difference, and there were no significant differences for the other variables.

Conclusion: We observed a fluctuation of academic performance among PIMESP students, towards inferior outcomes, when compared to BC students, throughout the first three years of medical school, but not for other variables. No increase in the dropout rate was observed, contrary to what is found in the literature.

Keywords: Medical Education; Affirmative Actions; Medical Students; Academic Performance

${ }^{1}$ Faculdade de Medicina de São José do Rio Preto, São José do Rio Preto, São Paulo, Brasil.

Editora-chefe: Rosiane Viana Zuza Diniz.| Editor associado: Gustavo Antonio Raimondi.

Recebido em 14/10/21; Aceito em 23/11/21. | Avaliado pelo processo de double blind review. 


\section{INTRODUÇÃO}

A educação é uma atividade fundamental em qualquer sociedade, considerada um dos fatores de desenvolvimento socioeconômico. Trata-se de um componente importante para o desenvolvimento sociocultural, político e econômico da sociedade e dos cidadãos ${ }^{1,2}$.

Durante o último século, ocorreu um grande desenvolvimento econômico, devido, em grande parte, à ciência e à educação. Assim, houve a necessidade de definir a educação não somente em relação ao seu efeito sobre o crescimento econômico, mas também no que concerne ao desenvolvimento humano ${ }^{3}$, e isso reafirma que o ensino superior e a escola são vistos como motores do desenvolvimento econômico ${ }^{2}$. Essa ideia é disseminada como uma solução para os problemas das desigualdades existentes entre os países e os indivíduos².

O reconhecimento do racismo e da discriminação racial como mecanismos de estruturação das desigualdades sociais no Brasil foi admitido pelo Estado a partir da década de 1990. Foram criadas políticas públicas específicas destinadas a promover os direitos da população negra ${ }^{4}$.

Entre essas desigualdades, destaca-se o acesso ao ensino superior em que de $60 \%$ a $65 \%$ dos negros têm desvantagem em relação aos brancos quanto às taxas de frequência ao ensino superior, segundo o Censo de 2010 4 .

Ao longo da história, o ensino superior no Brasil foi restrito aos representantes das classes economicamente mais elevadas, sendo poucos os exemplos de indivíduos oriundos de estratos mais baixos da sociedade a conseguir adentrar o meio acadêmico, progredir e se manter durante o curso de sua escolha, em especial na Medicina ${ }^{6}$.

Propuseram-se então, para reverter esse quadro desigual e promover a inclusão e diversidade, a criação e a instituição de ações afirmativas. Conforme Gomes ${ }^{7}$ :

[...] ações afirmativas podem ser definidas como um conjunto de políticas públicas e privadas de caráter compulsório, facultativo ou voluntário, concebidas com vistas ao combate à discriminação racial, de gênero e origem nacional, bem como para corrigir os efeitos presentes da discriminação praticada no passado, tendo por objetivo a concretização do ideal de efetiva igualdade de acesso a bens fundamentais como a educação e o emprego (p. 40) ${ }^{8}$.

Essas políticas têm origem conhecida na Índia, na década de 1940, e eram conhecidas como "políticas de reserva" e não "ação afirmativa". Implementou-se o primeiro sistema de cotas em benefício de castas inferiores no Parlamento por motivos religiosos, e, posteriormente, as cotas foram ratificadas pela Constituição de $1947^{2,8,9}$. Nos Estados Unidos, as políticas de ação afirmativa foram criadas na década de 1960, e, nesse processo, a mobilização política e social conhecida como Civil
Rights Movement teve um papel decisivo. Em julho de 1964, foi aprovado no Congresso norte-americano o Civil Rights Act com medidas antidiscriminação que se tornaram lei federal. $\mathrm{Na}$ educação superior, tanto as instituições públicas como as privadas foram compelidas a adotar programas de ação afirmativa. No caso das instituições privadas, elas são, em grande parte, dependentes do dinheiro público que chega até elas por meio de bolsas e financiamento de pesquisas. O objetivo dessas ações era promover a diversidade e os benefícios educacionais decorrentes ${ }^{9}$. Ainda que a experiência indiana seja a mais antiga, foi a experiência norte-americana que exerceu maior influência no Brasil ${ }^{8,9}$.

No Brasil é difícil estabelecer qual foi a primeira experiência histórica com ação afirmativa. Rosana Heringer ${ }^{10}$ toma como pioneira a Lei do Boi, que em 1968 reservou vagas nas universidades para filhos de fazendeiros, enquanto Sabrina Moehlecke ${ }^{11}$ acredita que o marco legal para a ação afirmativa começou com a Constituição de 1988, que já previa uma reserva dos cargos públicos para pessoas com deficiências físicas e mentais ${ }^{9}$.

Então, a adoção de ações afirmativas se deu após um processo de redemocratização, em que diferentes grupos e organizações raciais passaram a exigir direitos de maneira organizada e pública ${ }^{8,9}$. Tendo em vista esse cenário, após a redemocratização do país e depois da aprovação da nova Constituição nacional, iniciou-se, durante a década de 1990, a discussão sobre o tema e sobre a elaboração de políticas para democratizar o acesso à educação superior e, assim, servir como instrumento de transformação racial ${ }^{12-14}$.

Em 1995, houve a realização da marcha "Zumbi dos Palmares contra o Racismo, pela Cidadania e Vida", cuja comissão executiva nacional apresentou ao governo federal um documento enfatizando a necessidade de contemplar o problema da discriminação racial na agenda política nacional e de criar e implementar políticas para a promoção da igualdade. Esse documento, entre outras recomendações, incluía a adoção de ações afirmativas no ensino superior para candidatos negros ${ }^{8}$.

Nesse cenário, em 1999 e 2000 foram apresentados no Congresso Nacional dois projetos de lei (PLs) que previam a criação de ações afirmativas: o PL n 73 de 1999, que originou a Lei de Cotas, e o PL n 3.198 de 2000, que originou o Estatuto da Igualdade Racial ${ }^{8}$. Os debates sobre a adoção de ações afirmativas no Brasil aumentaram após o país participar da "Conferência Mundial contra o Racismo, Discriminação Racial, Xenofobia e Intolerância Correlata" realizada em Durban (África do Sul), em $2001^{4}$. Esse evento pode ser considerado como um momento especial no processo de implantação de políticas afirmativas no Brasil, como suporte de acesso 
ao mercado de trabalho e às universidades, tendo como público-alvo os estudantes das escolas da rede pública, de baixa renda e também aqueles grupos autodeclarados pretos, pardos e indígenas ${ }^{2}$.

As primeiras instituições brasileiras de ensino a adotar Programas de Ações Afirmativas (PAAs) com prioridade para critérios sociais e/ou raciais foram a Universidade do Estado do Rio de Janeiro (Uerj) e a Universidade Estadual do Norte Fluminense Darcy Ribeiro (Uenf) em 2000, e a Universidade de Brasília (UnB) em 2003,9. Também foram pioneiras a Universidade Estadual de Mato Grosso do Sul (Uems) e a Universidade Estadual da Bahia (UEB) ${ }^{2}$. Apesar de os primeiros sistemas de cotas terem sido direcionados a estudantes negros, a maior parte das universidades estaduais adotou critérios sociais que favoreciam estudantes oriundos de escolas públicas ${ }^{4}$.

Como a Lei no 12.711/2012 referia-se à questão das ações afirmativas em instituições federais, a partir de 2012 os reitores das universidades paulistas e o governo do estado de São Paulo iniciaram discussões sobre a criação de algo semelhante à Lei de Cotas, para assim, regulamentar as ações afirmativas nas instituições estaduais de ensino. Em 2013, surgiu o Programa de Inclusão com Mérito no Ensino Superior Público Paulista (Pimesp), no qual cada instituição de ensino superior é livre para decidir sobre a aplicação das ações e a proporção de vagas destinadas a elas ${ }^{15,16}$.

A partir de 2002, a inserção dos cotistas no contexto universitário exacerba os debates sobre os desdobramentos dessa política e os impactos da sua adoção. Esses debates resultam em estudos que incluem abordagens sobre a percepção avaliativa sobre as cotas dos diferentes alunos no contexto universitário, sua convivência entre diferentes classes e grupos étnicos, o debate em torno da meritocracia e isonomia, a trajetória dos alunos na graduação, o viés do debate sobre as ações afirmativas e as dificuldades de permanência na universidade ${ }^{17}$.

Depois de quase 20 anos desde o início da materialização das ações afirmativas, ainda há muita discussão sobre a real efetividade dessas medidas, e principalmente vários questionamentos têm sido feitos sobre o desempenho quando se comparam "cotistas" e "não cotistas", surgindo dúvidas se aqueles conseguem acompanhar estes, com estudos concluindo que os "cotistas" têm desempenho bem abaixo dos outros. Há ainda estudos que mostram que ambas as categorias têm desempenho equivalente, e outros que apontam ligeira vantagem para os ingressantes via ações afirmativas ${ }^{14,18-20}$.

No contexto das políticas estaduais, a Faculdade de Medicina de São José do Rio Preto (Famerp) aderiu ao Pimesp no ano de 2014 , reservando $15 \%$ do total de vagas de todos os seus cursos segundo critérios socioeconômicos raciais. Para o curso de Medicina, isso representa um total de 12 vagas, das quais quatro são reservadas para estudantes autodeclarados pretos, pardos ou indígenas, e o restante é direcionado para alunos que cursaram integralmente os ensinos fundamental e médio em escolas públicas.

Assim, o presente estudo tem por objetivo traçar um perfil do desempenho acadêmico, e outros aspectos diretamente relacionados à vida acadêmica, dos alunos do curso de Medicina da Famerp selecionados via Pimesp. Comparam-se ainda o desempenho acadêmico e os demais aspectos relacionados à vida acadêmica dos alunos Pimesp com os demais discentes de suas respectivas turmas selecionados via ampla concorrência.

\section{MÉTODOS}

Trata-se de estudo com coorte retrospectiva baseada no desempenho acadêmico de ingressantes pelo Pimesp $(P)$ e por ampla concorrência (AC), no triênio 2015/2017, desenvolvido no ano de 2017 e 2018, após o Parecer n².067.522, de 17 de maio de 2017, do Comitê de Ética em Pesquisa (CEP) da Famerp. Nesse parecer, solicitou-se a dispensa do Termo de Consentimento Livre e Esclarecido (TCLE), por tratar-se de levantamento de dados em banco de dados ou similar, endossado pelo artigo IV da Resolução n 466/2012 do Conselho Nacional de Saúde ${ }^{21}$. A dispensa foi concedida.

\section{Amostra}

Constituíram a amostra todos os alunos do curso de Medicina da Famerp, aprovados, regularmente matriculados e cursando, a partir do ano de 2015 - ano no qual se iniciouse o processo seletivo com Pimesp - até os alunos aprovados, regularmente matriculados e cursando no ano de 2017, ano do último vestibular anterior à coleta de dados, num total de 237 participantes. A amostra foi dividida em três grupos:ingressantes de 2017, que haviam cursado a primeira série; ingressantes de 2016, que haviam cursado a primeira e segunda séries; e ingressantes de 2015, que haviam cursado a primeira, segunda e terceira séries do curso. Cada grupo foi subdividido em dois subgrupos para análise: alunos cursando que ingressaram via Pimesp e alunos cursando que ingressaram via AC.

\section{Dados levantados}

Os dados foram levantados pelos pesquisadores valendo-se de registros institucionais das seguintes fontes de dados: Sistema de Gestão Famerp (SGF), sistema integrado de gestão escolar localmente desenvolvido; Serviço de Biblioteca e Documentação Científica (SBDC) Prof. Dr. José Victor Maniglia, por meio do software para gestão de bibliotecas SophiA ${ }^{\oplus}$ 2021 Prima; Diretoria Adjunta de Ensino (DAE), que detém 
os registros dos dados das monitorias na Famerp; Diretoria Adjunta de Extensão (DAEx), que detém os registros dos dados das ligas acadêmicas na Famerp; Centro Acadêmico Euryclides Zerbini (Caez), centro acadêmico do curso de Medicina, e sua respectiva Atlética, na Famerp.

Incluíram-se os seguintes dados: rendimento escolar, representado pela média aritmética simples $(M)$ das notas finais das disciplinas da estrutura curricular da série; situação final (SF: aprovação, aprovação com avaliação final ou avaliação pós-letiva ou reprovado); frequência (F); títulos tomados por empréstimo na biblioteca; e participação em atividades extracurriculares (participação em monitorias, participação em órgãos não colegiados de representação estudantil, como centro acadêmico e atlética, e em ligas acadêmicas).

\section{Análise de dados}

A análise exploratória dos dados incluiu média, mediana, desvio padrão e variação para variáveis contínuas e número e proporção para variáveis categóricas ${ }^{22}$. A distribuição normal ou não das variáveis contínuas foi analisada por assimetria, curtose e teste de Kolmogorov-Smirnov. Realizou-se a comparação de variáveis numéricas entre grupos pelo teste de Mann-Whitney, e a comparação de variáveis categóricas entre grupos foi feita pelo teste qui-quadrado de Pearson ${ }^{22-24}$. Realizou-se análise estatística por meio do software IBM-SPSS Statistics versão 24 (IBM Corporation, NY, USA). Todos os testes foram bicaudais, e consideraram-se valores de $p<0,05$ significantes.

\section{RESULTADOS}

Dos 237 alunos incluídos na amostra, todos haviam concluído a primeira série (ingressantes de 2015, 2016 e 2017); 158 alunos (ingressantes de 2015 e 2016), a primeira e segunda séries; e 78 (32,9\%) haviam concluído a terceira série (ingressantes de 2015) do curso de Medicina no momento da pesquisa. Os resultados foram organizados e serão descritos por série cursada. Cabe ressaltar que, para o período estudado, não houve alterações na estrutura curricular, nos calendários ou docentes que ministraram as disciplinas da estrutura curricular.

\section{Resultados relativos ao desempenho global observado na primeira série do curso de Medicina}

Dentre os 237 alunos que cursaram a primeira série (ingressantes de 2015, 2016 e 2017), 38 (16\%) foram ingressaram no curso de Medicina por meio do Pimesp. As características do desempenho global dos 237 alunos estão descritas na Tabela 1.

Os dados comparativos do desempenho dos estudantes podem ser vistos na Tabela 2.
$\mathrm{Na}$ análise comparativa entre os grupos de alunos ingressantes por AC e Pimesp, pode-se observar diferença significante nas médias das notas finais das disciplinas da estrutura curricular da primeira série: 8,04 \pm 0,48 e 7,67 $\pm 1,06$ para alunos $A C$ e Pimesp, respectivamente ( $p=0,028$ ), bem como para resultado final aprovado em número de matérias, maior para alunos $A C(p=0,01)$. Quanto à participação em atividades extracurriculares, houve maior proporção de alunos AC em ligas acadêmicas na primeira série de medicina, quando comparados aos alunos Pimesp $(p=0,012)$.

\section{Resultados relativos ao desempenho global observado na segunda série do curso de Medicina}

Cursaram a segunda série de Medicina 158 alunos (ingressantes de 2015 e 2016), dos quais 25 (15,8\%) haviam ingressado no curso por meio do Pimesp. Quanto à situação final do aluno, nessa série houve apenas alunos com a situação "aprovado" (Tabela 3).

Nessa etapa do curso, não houve diferença significante entre as médias das notas finais: 8,73 $\pm 0,36$ e 8,71 $\pm 0,42$ para alunos AC e Pimesp, respectivamente $(p=0,83)$, bem como no resultado final dos alunos, em número de matérias. $A$ única atividade extracurricular que apresentou diferença significante entre os grupos foi a participação em ligas acadêmicas, 119 $(91,5 \%)$ e $16(72,7 \%)$ de alunos AC e Pimesp participantes de ligas, respectivamente $(p=0,020)$.

Tabela 1. Desempenho global dos alunos observado na primeira série de Medicina (ingressantes de 2015, 2016 e 2017 - Famerp, 2018.

\begin{tabular}{cc}
\hline Característica & $\mathbf{n = 2 3 7}$ \\
\hline Notas $^{\mathrm{a}}$ & $7,98 \pm 0,63$ \\
Frequência, \% & $94,7(82,36-100)$ \\
\hline
\end{tabular}

Resultado final do aluno, número de matérias

Aprovado

$11(2-19)$

Aprovado após avaliação final

$1(0-5)$

Aprovado após período letivo

$0(0-4)$

Reprovado

$0(0-8)$

Retiradas de livros na biblioteca

$48(0-172)$

Participação em monitorias, n (\%)

$49 / 155(31,6)$

Participação em centro acadêmico/ atlética, n (\%)

$33 / 235$ (14)

Participação em ligas acadêmicas

$192 / 234(82,1)$

Variáveis contínuas estão descritas em média \pm desvio padrão ou mediana (variação); variáveis categóricas estão descritas em número (porcentagem).

aMédia aritmética simples das notas finais de todas as disciplinas da estrutura curricular da série cursada.

Fonte: Elaborada pelos autores. 
Tabela 2. Análise comparativa do desempenho dos alunos observado na primeira série de Medicina (ingressantes de 2015,2016 e 2017) - Famerp, 2018.

\begin{tabular}{|c|c|c|c|}
\hline Característica & $\begin{array}{l}\text { Ingressantes via Pimesp } \\
\qquad \mathrm{n}=\mathbf{3 8}\end{array}$ & $\begin{array}{c}\text { Ingressantes via } A C \\
n=199\end{array}$ & Valor $p$ \\
\hline Notas $^{a}$ & $7,67 \pm 1,06$ & $8,04 \pm 0,48$ & 0,028 \\
\hline Frequência, \% & $94,05(83,5-99,6)$ & $94,9(82,4-100)$ & 0,392 \\
\hline \multicolumn{4}{|l|}{ Resultado final do aluno, número de matérias } \\
\hline Aprovado & $10(2-12)$ & $11(5-12)$ & 0,01 \\
\hline Aprovado após avaliação final & $1(0-5)$ & $0(0-5)$ & 0,029 \\
\hline Aprovado após período letivo & $0(0-2)$ & $0(0-4)$ & 0,039 \\
\hline Reprovado & $0(0-8)$ & $0(0-1)$ & 0,061 \\
\hline Retiradas de livros na biblioteca & $46(4-126)$ & $48(0-172)$ & 0,637 \\
\hline \multicolumn{4}{|l|}{ Participação em monitorias, $n$ (\%) } \\
\hline Sim & $8(33,3)$ & $41(31,3)$ & \multirow{2}{*}{0,844} \\
\hline Não & $16(66,7)$ & $90(68,7)$ & \\
\hline \multicolumn{4}{|l|}{ Centro acadêmico/atlética, n (\%) } \\
\hline Sim & $4(10,5)$ & $29(14,7)$ & \multirow{2}{*}{0,496} \\
\hline Não & $34(89,5)$ & $168(85,3)$ & \\
\hline \multicolumn{4}{|l|}{ Ligas acadêmicas, n (\%) } \\
\hline Sim & $25(67,6)$ & $167(84,8)$ & \multirow{2}{*}{0,012} \\
\hline Não & $12(32,4)$ & $30(15,2)$ & \\
\hline
\end{tabular}

Variáveis contínuas estão descritas em média \pm desvio padrão ou mediana (variação); variáveis categóricas estão descritas em número (proporção).

aMédia aritmética simples das notas finais de todas as disciplinas da estrutura curricular da série cursada.

Pimesp: Programa de Inclusão com Mérito no Ensino Superior Público Paulista; AC: ampla concorrência.

Fonte: Elaborada pelos autores.

Tabela 3. Desempenho global dos alunos observado na segunda série de Medicina (ingressantes de 2015 e 2016) - Famerp, 2018.

\begin{tabular}{cc}
\hline Característica $^{\mathrm{a}}$ & $\mathbf{n}=\mathbf{1 5 8}$ \\
\hline Notas $^{\mathrm{a}}$ & $8,73 \pm 0,37$ \\
Frequência, \% & $95,8(77,7-100)$ \\
\hline
\end{tabular}

Resultado final do aluno, número de matérias

Aprovado 14 (4-15)

Aprovado após avaliação final $\quad 0(0-3)$

\begin{tabular}{cc} 
Reprovado & $0(0-4)$ \\
\hline Retiradas de livros na biblioteca & $23(0-143)$ \\
Monitoria, n (\%) & $48 / 153(31,4)$ \\
Centro acadêmico/atlética, n (\%) & $54 / 153(35,3)$ \\
Participação em ligas acadêmicas, n (\%) & $135 / 152(88,8)$ \\
\hline
\end{tabular}

Variáveis contínuas estão descritas em média \pm desvio padrão ou mediana (variação); variáveis categóricas estão descritas em número (porcentagem).

a Média aritmética simples das notas finais de todas as disciplinas da estrutura curricular da série cursada.

Fonte: Elaborada pelos autores.

\section{Resultados relativos ao desempenho global observado na terceira série do curso de Medicina}

Cursaram a terceira série de Medicina 78 alunos (ingressantes de 2015), dos quais $12(15,4 \%)$ haviam ingressado ao curso por meio do Pimesp. Quanto ao resultado final do aluno (número de matérias), não houve reprovações nessa série. A Tabela 4 mostra as características gerais de desempenho e participação em atividades extracurriculares dos alunos analisados.

Os dados comparativos do desempenho dos alunos nessa etapa podem ser vistos na Tabela 5.

Nessa etapa do curso, houve, novamente, diferença significante entre as médias das notas finais das disciplinas da estrutura curricular: $8,02 \pm 0,55$ e 8,32 $\pm 0,38$ para alunos Pimesp e $A C$, respectivamente $(p=0,032)$. Além disso, o resultado final do aluno, em número de matérias aprovadas, foi maior para alunos $A C(p=0,02)$. Não houve diferença significante com relação a frequência nas aulas, empréstimo de livros e participação em atividades extracurriculares. 


\section{DISCUSSÃO}

Embora seja patente que a adoção de políticas públicas de inclusão trouxe grandes mudanças no perfil do estudante de Medicina das instituições que as possuem, bem como a sua efetividade em democratizar o acesso à graduação médica, com maior pluralidade demográfica, social, econômica e étnica ${ }^{25}$, não parece haver consenso devido muito provavelmente à escassez de pesquisas nesse mister, no que concerne ao desempenho, à permanência no curso e às perspectivas quanto ao futuro profissional desses estudantes quando comparados aos que ingressam no curso pela ampla concorrência, ou seja, os reais impactos das políticas afirmativas de inclusão no desempenho do profissional médico.

Os métodos de seleção usados pelas escolas de Medicina devem identificar com segurança se os candidatos têm probabilidade de ser bem-sucedidos no treinamento médico e, em última instância, tornar-se médicos competentes. No entanto, há pouco consenso sobre os métodos que avaliam de forma confiável atributos não acadêmicos, e os estudos longitudinais examinando preditores de sucesso após a qualificação são insuficientes ${ }^{26}$.

Os estudos nacionais e internacionais mostram desempenho final similar ou até superior de estudantes admitidos no ensino superior por ações afirmativas e até por medidas judiciais ${ }^{27}$, baseados, quase que exclusivamente, no rendimento e nos atributos acadêmicos ${ }^{27,28}$. Ainda assim, via de regra, concluem salientando a necessidade de programas

Tabela 4. Desempenho global dos alunos observado na terceira série de Medicina (ingressantes de 2015) Famerp, 2018.

\begin{tabular}{cc}
\hline Característica & $\mathbf{n = 7 8}$ \\
\hline Notas $^{\mathrm{a}}$ & $8,27 \pm 0,42$ \\
Frequência, \% & $95,7(84,9-99,9)$ \\
\hline Resultado final do aluno, número de matérias & \\
Aprovado & $11(7-11)$ \\
Aprovado após avaliação final & $0(0-3)$ \\
Aprovado após período letivo & $0(0-1)$ \\
\hline Retiradas de livros & $21(0-110)$ \\
Monitoria, $\mathrm{n}$ (\%) & $2 / 75(2,7)$ \\
Centro acadêmico/atlética, $\mathrm{n}(\%)$ & $20 / 75(26,7)$ \\
Participação em ligas acadêmicas & $53 / 75(70,7)$ \\
\hline
\end{tabular}

Variáveis contínuas estão descritas em média \pm desvio padrão ou mediana (variação); variáveis categóricas estão descritas em número (porcentagem).

aMédia aritmética simples das notas finais de todas as disciplinas da estrutura curricular da série cursada.

Fonte: Elaborada pelos autores.

Tabela 5. Análise comparativa do desempenho dos alunos na terceira série de Medicina (ingressantes de 2015) - Famerp, 2018.

\begin{tabular}{|c|c|c|c|}
\hline Característica & $\begin{array}{l}\text { Ingressantes via Pimesp } \\
\qquad n=11\end{array}$ & $\begin{array}{l}\text { Ingressantes via } A C \\
n=64\end{array}$ & Valor $p$ \\
\hline Notas $^{\mathrm{a}}$ & $8,02 \pm 0,55$ & $8,32 \pm 0,38$ & 0,032 \\
\hline Frequência, \% & $94,7(84,9-99,5)$ & $95,8(85,6-99,9)$ & 0,327 \\
\hline \multicolumn{4}{|l|}{ Resultado final do aluno, número de matérias } \\
\hline Aprovado & $11(7-11)$ & $11(9-11)$ & 0,022 \\
\hline Aprovado após avaliação final & $0(0-3)$ & $0(0-2)$ & 0,022 \\
\hline Aprovado após período letivo & $0(0-0)$ & $0(0-1)$ & 0,016 \\
\hline Retiradas de livros & $23(2-57)$ & $21(0-110)$ & 0,544 \\
\hline \multicolumn{4}{|l|}{ Monitoria, $n(\%)$} \\
\hline Sim & $0(0)$ & $2(3,1)$ & \multirow{2}{*}{1,00} \\
\hline Não & $11(100)$ & $62(96,9)$ & \\
\hline \multicolumn{4}{|l|}{ Centro acadêmico/atlética, n (\%) } \\
\hline Sim & $3(27,3)$ & $17(26,6)$ & \multirow{2}{*}{1,00} \\
\hline Não & $8(72,7)$ & $47(73,4)$ & \\
\hline \multicolumn{4}{|l|}{ Participação em ligas acadêmicas, n (\%) } \\
\hline Sim & $7(63,6)$ & $46(71,9)$ & \multirow{2}{*}{0,721} \\
\hline Não & $4(36,4)$ & $18(28,1)$ & \\
\hline
\end{tabular}

Variáveis contínuas estão descritas em média \pm desvio-padrão ou mediana (variação); variáveis categóricas estão descritas em número (proporção).

aMédia aritmética simples das notas finais de todas as disciplinas da estrutura curricular da série cursada.

Pimesp: Programa de Inclusão com Mérito no Ensino Superior Público Paulista; AC: ampla concorrência.

Fonte: Elaborada pelos autores. 
consistentes para garantir a permanência e a conclusão do curso, com foco nas estratégias pedagógicas e no desenho curricular (de cunho acadêmico), e no apoio social e psicoemocional para minimizar possíveis impactos de adaptação à nova realidade ${ }^{29}$.

O desempenho acadêmico, via de regra também denominado rendimento escolar ${ }^{30}$, é baseado em uma ou mais avaliações de sala de aula num determinado período, diversificadas em sua forma e determinadas por características inerentes ao professor (mais ou menos exigente). Contudo, na instituição estudada todos os alunos cursam as mesmas disciplinas e com os mesmos professores, o que permite a comparação entre turmas do mesmo curso.

Destarte o relato de uma experiência pioneira em uma universidade italiana, onde grupo de interesse e grupo controle tinham o mesmo ano de ingresso, aulas, programas, professores e salas de aula idênticos, tornando a comparação dos dois grupos altamente válida e melhorando a confiabilidade dos dados $^{27}$, há que se levar em conta que se tratava de um grupo de interesse constituído por alunos que não foram aprovados no teste de admissão e não de um ingresso por ação afirmativa. Não é o caso aqui, quando o grupo de interesse inclui alunos que foram aprovados no teste de admissão, embora embasado numa política de ação afirmativa que garantia uma competição entre estudantes que tiveram oportunidades educacionais semelhantes até o momento em que se candidatam ao ingresso na universidade. Ainda assim nossa amostra, embora com anos de ingresso diferentes, teve as mesmas aulas, programas, professores e salas de aula idênticos, o que não torna a comparação dos grupos menos válida. Ademais, outros estudos importantes nesse mister foram levados a efeito nos mesmos moldes ${ }^{28}$.

Durante todo o período estudado, o rendimento escolar, observado a partir das médias das notas dos alunos ingressantes via $A C$, manteve-se maior quando comparado ao dos estudantes aprovados via Pimesp. Isso é observado, sobretudo, no primeiro ano da graduação, em que a diferença entre as notas é a maior entre todas as três séries analisadas. Porém, ao final do segundo ano, a diferença praticamente deixou de existir, tornando a média dos dois grupos praticamente a mesma. Entretanto, ao final da terceira série, observamos o reaparecimento de uma diferença, contudo inferior à apresentada ao final da primeira série.

Esse parece ser o aspecto mais explorado, ainda que pouco, na comparação entre alunos ingressante por AC e políticas públicas de inclusão, e não encontramos nenhum outro referencial especificamente envolvendo o Pimesp que explore esse quesito.

Alguns autores são categóricos em relação a isso. Pena et al. ${ }^{31}$, que analisaram alunos de Medicina da Universidade Federal de Ouro Preto (Ufop), ingressantes no ano de 2013, afirmam que "o desempenho acadêmico após o ingresso na universidade é equivalente entre cotistas e estudantes da ampla concorrência".

Embora a movimentação do alunado não tenha apresentado problemas, visto que não houve reprovações no período estudado, contrariando achados de Rocha et al. ${ }^{32}$ de que baixo desempenho acadêmico no início do curso é um fator preditivo de insucesso acadêmico, o item "situação final" apresentou diferença significativa no início do curso, assim como aconteceu com as notas, com os alunos AC apresentando desempenho final melhor que os alunos Pimesp, proporcionalmente, com mais aprovações diretas. Nesse item, o comportamento observado com as médias das notas voltou a se repetir, com as diferenças deixando de ser significativas ao final do segundo ano e voltando a aparecer ao final do terceiro ano.

Outro parâmetro analisado que mostrou significância foi o item "ligas acadêmicas". Ao final do primeiro ano, vemos que $82,1 \%$ do total de alunos haviam participado de ligas, e os alunos AC frequentaram mais que os alunos Pimesp (84,8\% daqueles contra $67,6 \%$ destes; diferença de 17,2\%). Para o segundo ano, o total de alunos que cursaram as ligas aumentou (88,8\%), e a diferença entre as categorias continuou a ter significância, com os alunos AC participando em maior quantidade (91,5\% contra 72,7\%; diferença de 18,8\%), com a diferença relativa entre eles permanecendo praticamente constante. Entretanto, no terceiro ano, a participação global de alunos em ligas diminui, passando para $70,7 \%$ do total, bem como a diferença de participação dos grupos (71,9\% para AC e 63,6\% para Pimesp; diferença de 8,3\%), não tendo, assim, significância entre os valores, evidenciando um fator de aproximação entre os grupos.

Há que se levar em conta que frequentar ligas acadêmicas requer tempo, que pode ser precioso para o aluno cotista não só para minimizar as eventuais deficiências dos ensinos básico e médio de qualidade inferior ao que seus colegas tiveram, mas também para procurar equilibrar os problemas resultantes das condições socioeconômicas, já que a literatura mostra que alunos cotistas, independentemente da modalidade, em sua grande maioria não recebem ajuda financeira da família ${ }^{33}$.

Eles enfrentam desafios únicos à medida que se integram a um ambiente principalmente de classe média a alta na Faculdade de Medicina, e as escolas devem ser sensíveis às necessidades dos alunos, tanto auxiliando na aculturação quanto reconsiderando como os currículos de competências culturais abordam as disparidades socioeconômicas ${ }^{34}$.

Quando se analisam os resultados das séries separadamente, a ideia de que os alunos AC apresentam desempenho superior ao dos aprovados por meio do Pimesp é reforçada ${ }^{17}$. Quando se comparam os dois primeiros anos, observa-se que as diferenças apresentadas pelos dois grupos 
diminuem, reforçando a ideia de que as diferenças tendem a desaparecer ${ }^{35}$. Entretanto, as informações referentes ao terceiro ano mostram um cenário diferente, de reaparecimento de disparidade entre os rendimentos dos grupos, porém com uma diferença menos acentuada do que a encontrada no início da graduação.

Ainda que estudos, sem fazerem distinção no método de entrada, demonstrem maior estresse devido à pressão excessiva em estudantes do ciclo básico quando comparado ao ciclo clínico ${ }^{36}$, há que se considerar que a mudança de ciclo, embora evoluindo para se tornar mais e mais imperceptível, ainda é uma fonte de estresse, trazendo novamente à baila a questão de se deparar com um cenário de uma dificuldade superior à vista anteriormente.

Outra explicação para essa flutuação poderia estar relacionada à autoavaliação e motivação. A autoavaliação é uma habilidade crítica complexa e desafiadora, em que a autocrítica pode oscilar entre sentimentos degradantes crônicos, também referida como síndrome do impostor, e avaliações autoinfladas ${ }^{37}$. Ansiedade e dúvidas significativas sobre a própria capacidade, particularmente nos anos iniciais do curso, podem prejudicar ainda mais o desempenho acadêmico. A motivação, por sua vez, é um processo psicológico que ativa o comportamento e o direciona para um objetivo. Graças à motivação, os alunos são capazes de se esforçar para persistir e atingir seus objetivos. Esse conceito inclui, como variáveis muito importantes relacionadas à personalidade, expectativas de realização, atribuições causais, autoeficácia, valor pessoal e, acima de tudo, autoestima e autoconceito, permeando novamente o campo da autoavaliação ${ }^{38}$. As crenças motivacionais influenciam o processo de antecipação das situações, seja com base nas crenças de autoeficácia, nas expectativas de resultados ou nas crenças do valor intrínseco ${ }^{39}$.

Também observamos que os dados encontrados contrariam a ideia de que as cotas contribuiriam para a piora na qualidade do curso, além de aumentarem os índices de evasão pela dificuldade dos cotistas em acompanhar o rendimento dos não cotistas ${ }^{17,40}$. As informações obtidas mostram que o número de alunos por sala se manteve praticamente constante, considerando o número máximo de 80 alunos em cada turma, achado esse corroborado por Pena et al. ${ }^{31}$, que, no curso de Medicina da Ufop, mencionam que não foi registrado nenhum desligamento ou cancelamento entre os cotistas.

Moreira $^{29}$ afirma que a trajetória entre a admissão e o curso de graduação, o desempenho ao longo da formação e, posteriormente, o desempenho profissional dependem de uma combinação complexa e individual de elementos, o que inclui condições prévias à graduação (em que os fatores socioeconômicos têm seu lugar), condições durante a graduação (o currículo, as experiências pedagógicas, a sensação de satisfação e o pertencimento ao grupo) e as condições após a graduação (mercado de trabalho e condições familiares e pessoais que definem a escolha de área para o exercício profissional futuro $)^{29}$.

No que tange às condições durante a graduação, o desafio da manutenção de um estudante na universidade é algo que, obviamente, se impõe a todo o alunado, marcadamente aqueles mais economicamente desfavorecidos, sobretudo no caso dos cursos que requerem dos estudantes investimentos em equipamentos pessoais, além da questão da integralidade do curso que exige dedicação praticamente exclusiva ${ }^{41}$.

Ainda que faltem recursos de vida acadêmica anterior, financeiros e culturais que expliquem o déficit dos estudantes cotistas (como a renda familiar e a necessidade do exercício de uma atividade laboral remunerada, dados não levantados aqui) e mesmo que a existência dessas diferenças possa ser vista pela ótica do privilégio branco na sociedade, rotineiramente tachada de "meritocracia", isso é questionável. Fomentando esse questionamento como um valor abstrato universal, que justifique a existência de alguma medida comum da aptidão e de inteligência da humanidade, e pressupondo que a meritocracia não pode ter uma definição excluída das circunstâncias sociais e materiais de vida das pessoas, a adoção de cotas não tem nada a ver com a exclusão do mérito e sim com a utilização de critérios de seleção que promovam a competição entre estudantes que tiveram oportunidades educacionais semelhantes até o momento em que se candidatam ao ingresso na universidade. Assim, os estudantes oriundos de escolas públicas, pretos, pardos e indígenas que serão selecionados representarão uma fração dos que postularam uma vaga na universidade e serão, portanto, os melhores entre eles ${ }^{42,43}$.

Contudo, alguns estudos, apesar de apontarem menor rendimento acadêmico para os beneficiados por qualquer tipo de bônus, não mostram nenhuma diferença na admissão à residência médica ${ }^{29}$ ou na repercussão no desempenho clínico posterior ${ }^{44}$. Esses estudos pressupõem que os estudantes socialmente menos favorecidos, após ingresso na graduação, por alguma estratégia inclusiva, tornam-se indistinguíveis dos demais ao final do curso ${ }^{45}$.

Enfim, nossos resultados nos levam a crer que, ao longo do curso, os estudantes se adaptam ao novo meio, passam a conhecer melhor as regras do jogo escolar, aprendem o ofício de aluno e se tornam universitários, independentemente da modalidade de ingresso ${ }^{31,46}$.

Ressalta-se ainda que há outros ganhos decorrentes da maior diversidade: a aproximação dos egressos do perfil da população na qual irão exercer suas profissões, capacita-os para lidar com a diversidade e aproveitar a riqueza de experiências 
que tal diversidade pode oferecer ${ }^{29}$.

Ao recrutarem, admitirem e apoiarem alunos de origens socioeconômicas mais baixas, as escolas de Medicina podem ganhar uma força de trabalho médica mais diversificada e quiçá seus egressos estarão mais propensos a servir a comunidades distintas, ajudando assim a lidar com as disparidades de saúde de nosso país continental.

\section{CONCLUSÕES / CONSIDERAÇÕES FINAIS}

Os resultados obtidos dão a entender que os alunos aprovados via Pimesp têm maior dificuldade ao se depararem com um cenário de complexidade superior à vista anteriormente. Isso é evidenciado por diferenças, tanto no início do curso quanto no começo do estudo mais específico para a área médica, quando se inicia o ciclo clínico.

Nossos dados também contrariam a ideia de aumento dos índices de evasão pela dificuldade dos cotistas em acompanhar o rendimento dos não cotistas, já que o número de alunos por sala se manteve praticamente constante.

Os outros aspectos diretamente relacionados à vida acadêmica, como títulos tomados por empréstimo na biblioteca e participação em atividades extracurriculares, não apresentaram diferenças significativas entre Pimesp e AC.

Esse comportamento dos parâmetros estudados, de aproximação e reaparecimento de uma disparidade, carece de uma investigação mais ampla no futuro, analisando um número maior de alunos e mais turmas, além de inserir os números referentes ao quarto ano do curso de Medicina, teoricamente o mais difícil e o que mais exige dos alunos na instituição de estudo, e os comparando aos coletados nas séries anteriores. Além disso, é necessário estimar se essas diferenças irão pesar na formação final do profissional de medicina ou se elas irão desaparecer na metade final do curso, não atrapalhando a prática médica futura desses estudantes.

É chegado o momento de encerrarem-se as comparações e convocar as instituições e seu corpo administrativo e docente para assumirem responsabilidades para garantir a oferta de condições de equidade.

\section{CONTRIBUIÇÃO DOS AUTORES}

Atílio Marcomini Neto e Patrícia da Silva Fucuta foram os responsáveis pela coleta, análise e interpretação dos dados, pela redação final dos resultados e pela análise estatística. Vânia Maria Sabadotto Brienze e Júlio César André redigiram o manuscrito final. Alba Regina de Abreu Lima e Sérgio Luís Aparecido Brienze realizaram a revisão crítica.

\section{FINANCIAMENTO}

Declaramos não haver financiamento.

\section{REFERÊNCIAS}

1. Delors J. Educação: um tesouro a descobrir. Relatório para a Unesco da Comissão Internacional sobre Educação para o Século XXI. Paris, Porto: Unesco, ASA; 1996 [acesso em 20 ago 2021]. Disponível em: http://www. dominiopublico.gov.br/.

2. Fritznel A. Análise do Programa de Ação Afirmativa e Inclusão Social (PAAIS) implementado pela UNICAMP no período de 2005-2014 [dissertação] Campinas: Universidade de Campinas; 2015 [acesso em 15 out 2021].

3. Frigotto G. Educação e crise do capitalismo real. 4a ed. São Paulo: Cortez; 2000. 41 p.

4. Aguiar MM, Piotto DC. Desigualdade à brasileira: capital étnico-racial no acesso ao ensino superior. Educação. 2018;41(3):478-491 [acesso em 9 ago 2021].

5. Corbucci PR. Evolução do acesso de jovens à educação superior no Brasil. Brasília: Ipea; 2014.

6. Chehuen Neto JA, Godinho ÍA, Barbosa RM, Barbosa GC, Ferreira RE. The medical school: opportunities offered and the affirmative action. Rev Méd Minas Gerais. 2014;24(2):188-195. doi: 10.5935/2238-3182.20140052

7. Gomes JBB. Ação afirmativa \& princípio constitucional da igualdade: o direito como instrumento de transformação social. A experiência dos EUA. Rio de Janeiro: Renovar; 2001

8. Anhaia BC. A "lei de cotas" no ensino superior brasileiro: reflexões sobre a política pública e as universidades federais [tese]. Porto Alegre: Universidade Federal do Rio Grande do Sul; 2019 [acesso em 20 ago 2021]. Disponível em: https://www.lume.ufrgs.br/bitstream/ handle/10183/196058/001094918.pdf?sequence $=1$

9. Feres Júnior J, Campos LA, Daflon VT, Venturini AC. Ação afirmativa: conceito, história e debates. Rio de Janeiro: EdUERJ; 2018 [acesso em 15 set 2021]. Disponível em: http://books.scielo.org/id/2mvbb.

10. Heringer R. Mapeamento de ações e discursos de combate às desigualdades raciais no Brasil. Estud Afro-Asiáticos. 2001;23(2):1-43.

11. Moehlecke S. Ação afirmativa: história e debates no Brasil. Cad Pesqui. 2002;(117):197-217 [acesso em 10 jul 2021]. Disponível em http://www.scielo.br/scielo.php?script=sci_arttext\&pid=S0100$15742002000300011 \&$ lng=pt\&tlng=pt.

12. dos Santos JHP, Santos IP. Da epistemologia à hermenêutica: compreendendo as ações afirmativas. Direito e Democr. 2013;14(2):82-95.

13. Daflon VT, Feres Júnior J, Campos LA. Ações afirmativas raciais no ensino superior público brasileiro: um panorama analítico. Cad Pesqui. 2013;43(148):302-27 [acesso em 30 jul 2021]. Disponível em: from: http://www.scielo.br/scielo.php?script=sci_arttext\&pid=S0100$15742013000100015 \&$ lng $=$ pt\&tlng=pt.

14. de Souza JLS, Wust C, Kremer R, Pulga VL, Lousada VL. I Seminário políticas públicas e ações afirmativas Universidade Federal de Santa Maria Observatório de ações afirmativas. In: Políticas afirmativas e inclusão no curso de medicina da UFFPS/PF: rompendo paradigmas. Santa Maria: UFSM, Afirme, Observatório de ações afirmativas para acesso e permanência nas Universidades Públicas da América do Sul, 2015 [acesso em 15 mar 2021].

15. Minto LW. Ensino médio e ensino superior em São Paulo: notas críticas sobre o Pimesp. Educ em Rev. 2014;14(2):53-68.

16. Nogueira F. Cotas raciais no curso de medicina da UFRGS na perspectiva docente: rupturas e configurações tecidas na garantia do direito à educação superior pública [resumo]. Porto Alegre: Salão UFRGS 2016: III SALÃO EDUFRGS. Pontifícia Universidade Católica do Rio Grande do Sul; 2015 [acesso em 10 mai 2021]. Disponível em: https://lume.ufrgs br/bitstream/handle/10183/156860/EDUFRGS2016_Resumo_51808. pdf? sequence $=1$ \&isAllowed $=y$.

\section{CONFLITO DE INTERESSES}

Declaramos não haver conflito de interesses. 
17. Peixoto ALA, Ribeiro EMBA, Bastos AVB, Ramalho MCK. Cotas e desempenho acadêmico na Ufba: um estudo a partir dos coeficientes de rendimento. Avaliação Rev da Avaliação da Educ Super. 2016;21(2):569-92 [acesso em 30 jun 2021]. Disponível em: http://www.scielo.br/scielo.php?script=sci_ arttext\&pid=S1414-40772016000200569\&lng=pt\&tlng=pt.

18. Goldemberg J. Ações afirmativas nas universidades brasileiras. Jornal da USP 2016;2:4 [acesso em 18 abr 2020]. Disponível em: http://www. acadciencias.org.br.

19. De Assis YS. Relações sociais e sentidos de justiça social após a adoção da política de cotas na Universidade Federal de Sergipe. Rev TOMO 2014; 24: 297-334 [acesso em 10 mai 2021]. Disponível em: https://seer.ufs.br/index. php/tomo/article/view/3193.

20. Velloso J. Cotistas e não-cotistas: rendimento de alunos da Universidade de Brasília. Cad Pesqui. 2009;39(137):621-44 [acesso em 12 mai 2020]. Disponível em: http://www.scielo.br/scielo.php?script=sci_ arttext\&pid=S0100-15742009000200014\&lng=pt\&tlng=pt.

21. Brasil. Resolução $n^{\circ} 466$, de 12 de dezembro de 2012. Aprova as seguintes diretrizes e normas regulamentadoras de pesquisas envolvendo seres humanos. Brasília; 2012.

22. Conover WJ. Practical nonparametric statistics. New York: John Wiley \& Sons; 1998.

23. Siegel $\mathrm{S}$, Castellan NJ. Estatística não paramétrica para ciências do comportamento. 2a ed. Porto Alegre: Artmed; 2006. 488 p.

24. Field A. Descobrindo a estatística usando o SPSS. 5a ed. Porto Alegre: Grupo A; 2020. 1104 p.

25. Silva MLAM, Amaral E, Machado HC, Passeri SMRR, Bragança JF. Influência de políticas de ação afirmativa no perfil sociodemográfico de estudantes de Medicina de universidade brasileira. Rev Bras Educ Med. 2018;42(3):36-48.

26. Patterson F, Knight A, Dowell J, Nicholson S, Cousans F, Cleland J. How effective are selection methods in medical education? A systematic review. Med Educ. 2016;50(1):36-60.

27. MigliarettiG, Bozzaro S, Siliquini R, Stura I, Costa G, Cavallo F. Is the admission test for a course in medicine a good predictor of academic performance? A case-control experience at the school of medicine of Turin. BMJ Open. 2017 Nov 1;7(11):e017417. doi: 10.1136/bmjopen-2017-017417.

28. Moreira GO, Passeri S, Velho PENF, Ferraresi F, Appenzeller S, Amaral E. The academic performance of scholarship students during medical school. Rev Bras Educ Med. 2019;43(3):163-9 [acesso em 30 abr 2021]. Disponível em: http://www.scielo.br/scielo.php?script=sci_ arttext\&pid=S0100-55022019000300163\&tlng=en.

29. Moreira GO. Validade preditiva do processo seletivo para admissão em medicina e o papel das ações afirmativas em relação ao desempenho durante a graduação e na seleção para a residência médica [tese]. Campinas: Universidade Estadual de Campinas; 2017 [acesso em 10 ago 2020]. Disponível em: http://repositorioslatinoamericanos.uchile.cl/ handle/2250/1368259

30. Baccaro TA, Shinyashiki GT. O desenvolvimento da orientação profissional no Brasil. Rev Bras Orientaç Prof. 2003;4(2):1-11.

31. Pena MAC, Matos DAS, Coutrim RME. Percurso de estudantes cotistas: ingresso, permanência e oportunidades no ensino superior. Avaliação Rev da Avaliação da Educ Super. 2020;25(1):27-51 [acesso em 30 jan 2021]. Disponível em: http://www.scielo.br/scielo.php?script=sci_ arttext\&pid=S1414-40772020000100027\&tlng=pt.

32. Rocha BASR, Toledo Júnior A.Predictive factors of graduation delay in a medical program: a retrospective cohort study in Brazil, 2010-2016. Rev Bras Educ Med. 2020;44(1), e001 [acesso em 28 out 2021]. Disponível em: http://www.scielo. br/scielo.php?script=sci_arttext\&pid=S0100-55022020000100201\&tlng=en.
33. Souza PGA, Pôrto ACCA, Souza A, Silva Júnior AG, Borges FT. Perfil socioeconômico e racial de estudantes de Medicina em uma universidade pública do Rio de Janeiro. Rev Bras Educ Med. 2020;44(3), e090 [acesso em 28 out 2021]. Disponível em: http://www.scielo.br/scielo.php?script=sci_ arttext\&pid=S0100-55022020000300211\&tlng=pt.

34. Girotti JA, Park YS, Tekian A. Ensuring a fair and equitable selection of students to serve society's health care needs. Med Educ. 2015;49(1):84-92. doi: 10.1111/medu.12506.

35. Mendes Junior AAF. Uma análise da progressão dos alunos cotistas sob a primeira ação afirmativa brasileira no ensino superior: o caso da Universidade do Estado do Rio de Janeiro. Ens Avaliação e Políticas Públicas em Educ 2014;22(82):31-56 [acesso em 10 mai 2019]. Disponível em: http://www. scielo.br/scielo.php?script=sci_arttext\&pid=S0104-40362014000100003\&ln $\mathrm{g}=\mathrm{pt} \&$ tlng $=$ pt.

36. Loureiro EMF. Study of the relationship between stress and life style of Medical Students. Rev Bras Educ Med. 2008;32(2):273.

37. Villwock JA, Sobin LB, Koester LA, Harris TM. Impostor syndrome and burnout among American medical students: a pilot study. Int J Med Educ 2016 Oct 31;7:364-9 [acesso em 10 mai 2019]. Disponível em: http:// www.ijme.net/archive/7/impostor-syndrome-among-american-medicalstudents/.

38. Álvarez MMG. Estrategia metodológica para desarrollar el aprendizaje autorregulado em los estudiantes del primer ciclo de la carrera de administración em una universidad privada de Lima [tesis]. La Molina: Universidad San Ignacio de Loyola; 2020.

39. Salgado FAF, Polydoro SAJ, Rosário P. Programa de Promoção da Autorregulação da Aprendizagem de Ingressantes da Educação Superior. Psico-USF. 2018;23(4):667-79 [acesso em 10 mai 2019]. Disponível em: http://www.scielo.br/scielo.php?script=sci_arttext\&pid=S1413$82712018000400008 \&$ Ing $=$ pt\&tlng=pt.

40. Reibnegger G, Caluba H-CC, Ithaler D, Manhal S, Neges HM, Smolle J. dropout rates in medical students at one school before and after the installation of admission tests in Austria. Acad Med. 2011 Aug;86(8):10408 [acesso em 20 mai 2019]. Disponível em: http://journals.lww. com/00001888-201108000-00029.

41. Lopes MA, Braga MLDS. Acesso e permanência da população negra no ensino superior. Brasília: UNESCO 2007. 358 p.

42. Alves Filho M. Brasil já teve políticas afirmativas para brancos europeus. Jornal da Unicamp. 2017 [acesso em 30 out 2021]. Disponível em: https:// vermelho.org.br/2017/06/14/brasil-ja-teve-politicas-afirmativas-parabrancos-europeus/.

43. Chalhoub S. A meritocracia é um mito que alimenta as desigualdades. Jornal da Unicamp. 2017 [acesso em 10 abr 2019]. Disponível em: http:// verborragio.blogspot.com/2017/06/a-meritocracia-e-um-mito-quealimenta.html.

44. Cooter R, Erdmann JB, Gonnella JS, Callahan CA, Hojat M, Xu G. Economic diversity in medical education. Eval Health Prof. 2004 Sep 24;27(3):252-64. doi: $10.1177 / 0163278704267041$.

45. Wiliam D. What counts as evidence of educational achievement? The role of constructs in the pursuit of equity in assessment. Rev Res Educ. 2010 Mar 1;34(1):254-84. Doi: 10.3102/0091732X09351544.

46. Coulon A. A condição de estudante: a entrada na vida universitária. Salvador: Edufba; 2008. 278 p. 